\title{
In Memoriam \\ Ana María Haz Montaldo (1956-2010) \\ Profesora Asociada Escuela de Psicología UC
}

\author{
René Ríos F. \\ Profesor ISUC \\ Director Ejecutivo CEES-UC
}

\author{
Daniel Díaz y Lilian Canales \\ Psicólogos UC \\ Miembros asociados del CEES-UC
}

Ana María Haz Montaldo se ha ido, pero su impronta queda en muchos estudiantes y colegas. Humilde y metódica en su trabajo, supo decir "no sé", pidió ayuda sin pretensiones y puso lo mejor de sí en las tareas, proyectos y actividades que acometía con gran compromiso. Tras su apariencia de fragilidad tenía una fortaleza intelectual y personal no usual, que le daba la energía para luchar y sostener sus batallas, muchas de las cuales parecían inconmensurables.

Entre las temáticas de interés en las cuales trabajó se encuentran los emprendimientos sociales, maltrato infantil, violencia intrafamiliar, resiliencia, familias multi-problemáticas y voluntariado, generalmente asociadas a contextos de exclusión social. Sus trabajos sobre los abusos de la infancia sirvieron de base para el encuentro con otras disciplinas, interacción que sentó las bases para la creación del Centro de Estudios de Emprendimientos Solidarios (CEES-UC). Ana María ejerció como Directora Ejecutiva del mismo desde su creación, contribuyendo significativamente a posicionarlo frente a organizaciones solidarias y organismos del Estado como un referente para la reflexión y el acceso a nuevos conocimientos. Era, además, la directora alterna del proyecto FONDEF Avanzar en Calidad, cuyo propósito es desarrollar e instaurar un sistema de certificación de la calidad para los programas que realizan intervenciones sociales.

Le gustaba escribir en compañía, buscando rodearse de personas a quienes alentaba a poner sus ideas en papel. Era abierta a nuevas propuestas o esquemas que pudieran surgir en una conversación, pues nunca era su propósito demostrar que su opinión era la correcta, sino el de construir en conjunto ideas a las cuales era difícil atribuir un origen único y personal. Declaraba ex- plícitamente que escribir no era su fuerte y por ello buscaba trabajar con personas que contasen con la habilidad de poner en palabras esas ideas que surgen de la conversación y discusión colectivas, instancias que alentaba y disfrutaba.

Ana María se impacientaba con la desigualdad social que se manifiesta especialmente en la falta de opciones de servicios profesionales de calidad para las personas que se encuentran bajo diversas formas de exclusión, pobreza, maltrato y abuso. Esto la motivaba y mantenía en sus esfuerzos en torno a las actividades del CEES-UC, y también en su labor docente. Su entusiasmo no provenía de la ambición (legítima e incluso necesaria) de ser autora de soluciones para superar esas limitaciones, sino de la posibilidad de superar la injusticia social, que la indignaba. A muchos de sus estudiantes les aportó la visión de vincular el trabajo psicológico con esos programas sociales. Por eso mantuvo el curso de Salud Mental Comunitaria, un curso atípico que se ubicaba al final de la formación clínica en la Escuela de Psicología. Muchos estudiantes se encontraban con una cátedra que les cuestionó la práctica profesional solitaria y aislada, y les abría el campo de la práctica en comunidades. Su formación sociológica y enfoque sistémico la llevaron a desarrollar una visión del rol profesional del psicólogo y de su inserción en la sociedad. Sostenía que todo psicólogo debe comprender el contexto organizacional en que se desempeña, de manera de situar su aporte profesional en él, maximizando los potenciales beneficios de sus capacidades profesionales. Estaba muy consciente de que ello implicaba un sacrificio para la práctica individual, al requerir situarse en una segunda línea de intervención para brindar apoyo a quienes están en la primera línea. 
En otro de los cursos que realizó, Estrategias de Intervención, de quinto año de la carrera de psicología en su mención clínica, insertó la pre-práctica clínica de los estudiantes en contextos comunitarios a través de consultorios de atención primaria y en programas sociales, integrando sus conocimientos e intereses en el ámbito clínico y social.

No tenía problemas en parecer poco académica o "casuística", pues al no haber abandonado nunca la supervisión de la práctica clínica, contaba con una recopilación muy rica de casos que le permitía ejemplificar sus elaboraciones teóricas más amplias. Siempre tenía muy claro su mensaje último y parecía no tener inconvenientes en recorrer un camino poblado de casos, para luego terminar con interpelaciones claras, directas y hasta polémicas, si lo consideraba apropiado desde su punto de vista técnico. Así, en una charla a equipos de voluntariado universitario tituló su participación Trabajos Voluntarios: Cuando Dañar También es una Posibilidad (Haz, 2007, Julio).

$\mathrm{Y}$ es que tanto en quienes fueron sus alumnos directos como en otros estudiantes, especialmente quienes participan en voluntariados y/o profesionales más jóvenes, intentó sembrar inquietud por las temáticas sociales y el trabajo de calidad, por ofrecer intervenciones de excelencia para quienes no tienen la posibilidad de elegir en qué lugar o con quién ser atendidos.

Alguna vez contó que arribó al tema de maltrato infantil casi por accidente. Luego de desarrollar una tesis de grado con orientación organizacional (Anastassiou \& Haz, 1980) sintió el deber de buscar un tema de especialización, y notó que el ámbito de la violencia ejercida hacia menores tenía poco desarrollo en ese momento. Luego de trabajar sobre el tema durante años llegó al convencimiento acerca de la necesidad de modificar el enfoque centrado en la observación individual del profesional, técnico o voluntario, que lidia con problemas de alta complejidad psicológica y social, hacia uno en que se deben incluir los contextos institucionales donde estas personas desarrollan su labor. Su trabajo con el personal de la primera línea de intervención refrendó que los cambios más necesarios y fundamentales debían venir desde arriba hacia abajo. Señala en 2002 (Haz, Díaz \& Raglianti, 2002) que:

el abordaje (...) de los problemas (...) debe ser enfocado con una mirada interdisciplinaria, un enfoque necesariamente intersectorial y una visión de red (...). Estos tres elementos deberán estar presentes desde el momento de visualizar y conceptualizar el "problema", hasta cuando se piense en las "soluciones". Se trata de reconocer que las variables determinantes de los problemas están fragmentadas por todo el espacio humano e institucional, de manera tal que las soluciones deberán ser, consecuentemente, planteamientos que convoquen los trozos de solución que invariablemente estarán dispersos en los más insospechados nodos de la red. (p. 27)

Señala al final de ese escrito (Haz et al., 2002, p. 28) un llamado totalmente vigente:

Se torna imperioso que los nuevos profesionales aborden su profesión de una nueva manera, que tome a los clásicos como lo que son, autores que en su contexto socio-histórico hicieron un aporte fundamental, pero leerlos hoy como a profetas o iluminados no lleva más que a incurrir en un error de grandes proporciones, pues la acción conlleva una clara negación de una historia cuya característica esencial es el dinamismo, que evoluciona, que cambia permanentemente, y que no tan solo cambia a través del tiempo, sino que también muestra diferentes rostros en un mismo período, según sea el lugar, la cultura y el grupo social en que uno se sitúa, y desde el cual eleva la cabeza para observar el momento histórico-social que le tocó vivir.

Para ilustrar esta perspectiva adoptó un ejemplo que escuchó respecto de una máquina de perforación, cuyo extremo de 
corte se haya recubierto de diamantes. Para ella, esto significaba que toda institución de orientación social debe contar con una estructura completamente pensada y dirigida a la función que cumplen quienes están en la primera línea. De ahí su perseverancia en visualizar el lugar esencial que cumplen los equipos de trato directo en una intervención social, sin cuyo buen desempeño pierde sentido la totalidad de la organización. Todo se juega en esa primera línea. Para ella los organigramas no debieran tener a los jefes arriba, sino que a los operadores directos y todos los demás como su estructura de soporte.

Desde su visión, reconoció que todos los niveles son importantes en el trabajo, no cabe duda, pero, sin el bienestar de los equipos directamente involucrados con los usuarios, la naturaleza misma del trabajo que se desarrolla queda desvirtuada. Esta proposición determinó que su valioso y significativo aporte al modelo de gestión de calidad de las organizaciones sociales que desarrolla el CEES-UC haya sido la inclusión y desarrollo del componente de gestión de los equipos, orientado al cuidado y fortalecimiento de los equipos de trabajo en los programas y organizaciones sociales, para promover su bienestar, prevenir el desgaste laboral y así poder ofrecer un mejor servicio a sus usuarios.

Se exigía a sí misma para poder demandar de los demás que se hicieran las cosas bien. Le apasionaba su disciplina y la misma pasión encendía su valentía para decir las cosas por su nombre, aun cuando ello implicara caer mal o ser vista como excesivamente crítica. Se caracterizó por combinar esa pasión con una capacidad analítica contundente que le permitía observar las limitaciones que enfrentamos y encontrar las vías para superarlas. Esto la hacía ser combativa, tenaz y porfiada y, a la vez, atenta y solícita con los demás.

La Escuela de Psicología y el CEES-UC lamentan su partida, pero se sienten privilegiados de haber podido trabajar con una persona tan involucrada e interesada en los demás, especialmente en quienes carecen de las oportunidades que ella consideraba legítimo exigir para todos.

\section{Referencias}

Anastassiou, D., \& Haz A. M. (1980). Clima organizacional y clima psicológico: un intento por dirimir las diferencias (Tesis de Licenciatura no publicada), Escuela de Psicología, Pontificia Universidad Católica de Chile, Santiago, Chile.

Haz, A. M. (2007, Julio). Trabajos voluntarios: cuando dañar también es una posibilidad. Presentación en Capacitación para Voluntarios de Trabajos Voluntarios de la Pontificia Universidad Católica de Chile, Santiago, Chile.

Haz, A. M., Díaz, D. \& Raglianti, M. (2002). Un desafío vigente para el psicólogo clínico: el entendimiento de estrategias de intervención integrales para abordar problemas de riesgo psicosocial. Terapia Psicológica, 20, 23-28. 